\title{
EDITORIAL
}

\section{Mechanisms and implications of bone adipose tissue-mineral relationships}

\author{
European Journal of Clinical Nutrition (2012) 66, 979-982; \\ doi:10.1038/ejcn.2012.88
}

\section{BACKGROUND}

Although there has been extensive interest in the adverse effects of obesity on health and the role of fat distribution between and within different tissues, the significance of fat in the bone marrow has received relatively little attention. This issue of European Journal of Clinical Nutrition contains an article ${ }^{1}$ that reports an inverse relationship between intra-osseous adipose tissue volume, measured in the pelvis of adults using magnetic resonance imaging (MRI), and bone mineral density (BMD) of the pelvis, lumbar vertebrae and the whole body, measured using dual energy X-ray absorptiometry (DXA). They suggest that the two may be causally linked according to an existing hypothesis about mesenchymal stem cells, which can preferentially differentiate into adipocytes or osteoblasts. The paper not only raises questions about the biology of mineralisation and fat metabolism in bone, but also about the potential interaction between them and their relevance to the development of osteoporosis. To contextualise the new findings, it is helpful to first briefly consider the normal changes in both the fat and mineral content of bone which occur during the normal adult lifespan.

There has been some controversy about the age of peak bone mass using measurements of whole body BMD or bone mineral content (BMC) obtained by DXA. Some studies indicate that it occurs at 20-30 years ${ }^{2,3}$ (Iongitudinal and cross-sectional studies), but others suggest that it occurs later at 30-40 years ${ }^{4,5}$ and perhaps earlier in the late teens. ${ }^{6,7}$ The age varies according to gender, ethnicity, pubertal status, physical activity and genetic factors. It also varies according to the type of bone ${ }^{8-10}$ and even region within the same bone. ${ }^{8-10}$ Peak bone mass of the lumbar spine has generally been reported to occur at $20-40$ years ${ }^{8-14}$ but at the femoral neck, it has often been reported to occur earlier at around 20 years or even earlier. ${ }^{8-10}$ There appears to be little information about age of the peak bone mass of the pelvis. In the whole body little net bone loss generally occurs before the age of 40 years, although about a $10 \%$ reduction in BMD has been reported to occur at some sites. 8,10

The temporal pattern of change in bone fat differs from that of mineral in that it continues to accumulate in bone during the entire lifespan ${ }^{15-17}$ due to two major processes. First, red marrow (a homeopoietic tissue), which contains a smaller proportion of fat, is replaced by yellow fat, with a larger proportion of fat $(\sim 80 \%$ fat). ${ }^{15,18}$ At birth nearly all the marrow is red. In the young adult, red marrow is found predominantly in the vertebrae, skull, sternum, ribs, skull pelvis and the proximal ends of femurs and humerii, and in several of these bones (for example, vertebrae, sternum and ileum) red marrow continues to be replaced by yellow marrow during the remaining adult lifespan. ${ }^{15}$ Second, fat fills the space made available from the net loss of bone mineral, predominantly after the age of 40 years as part of the 'aging' process. As a result of both of these processes, the amount of bone marrow fat during the adult lifespan doubles in both males and females. In the reference $70 \mathrm{~kg}$ male there is $1.5 \mathrm{~kg}$ of red marrow and $1.5 \mathrm{~kg}$ yellow marrow $(1.3 \mathrm{~kg}$ of each in the reference $58 \mathrm{~kg}$ female). ${ }^{15}$

\section{INVERSE BONE MINERAL AND BONE FAT RELATIONSHIP}

Since fat accumulates in bone marrow, while mineral is lost especially after age 30-40 years, an inverse relationship between individuals of widely different adult ages is expected to exist, and many scanning studies support the information obtained from bone biopsy or autopsy studies. ${ }^{15,16}$ However, it is more difficult to conclude that the same inverse relationship applies to individuals of comparable age, especially since several studies examining bone adipose tissue (or fat)-mineral relationships have not adjusted for age. ${ }^{16,17,19-22}$ A few studies have adjusted for age, ${ }^{23,24}$ among them being the recent study of Shen et al. ${ }^{1}$ This last study stands out from others in that it has substantial power due to the large sample size (200 aged $18-40$ years and another $200>40$ years) and in demonstrating that the inverse bone adipose tissue-mineral relationship is robust, persisting in both the younger and older groups even after adjustment for multiple variables (age, weight, total body fat, subcutaneous adipose tissue, visceral adipose tissue, skeletal muscle, sex, ethnicity and menopausal status; $r$ values ranging from -0.155 and -0.266 ). The paper raises questions about the mechanisms responsible for the inverse bone adipose tissue-mineral relationship and the merits and limitations of different methodological approaches to assess such relationships.

\section{POSSIBLE MECHANISMS RESPONSIBLE FOR THE INVERSE BONE MINERAL-FAT RELATIONSHIP}

A key hypothesis supported by Shen et al. ${ }^{1}$ concerns mesangial stem cells that can differentiate into either osteoblasts or fat cells. ${ }^{25}$ Preferential differentiation into osteoblasts can help explain why more bone is associated with less fat, and vice versa. The hypothesis, which is based on experimental laboratory work, is attractive because it is conceptually simple, with a single event explaining partitioning of tissue into fat and bone. However, a number of alternative hypotheses can also be suggested. For example, a traditional explanation is that fat simply accumulates passively in the variable bone marrow space $^{26}$ made available during development and remodelling. However, this does not explain why the marrow space is not filled by extracellular fluid or another type of tissue/substance. Another hypothesis is that the biological variation in bone to marrow space, known to occur both before and after peak bone mass is attained, is due to the direct effect of regulated processes on mature bone cells associated with bone formation (osteoblasts) and/or bone resorption (osteoclasts) which occur simultaneously during the lifespan.

A distinctly different hypothesis is that metabolic processes in mature fat cells influence the function of mature bone cells (osteoblasts and/or osteoclasts) or vice versa. The location of bone fat in the trabercular area where remodelling is active raises the possibility of a functional metabolic relationships between the two types of cells, including the provision of energy by fat cells to allow osteoblasts and osteoclasts to remodel bone. ${ }^{27}$ The possibility of cross-talk between fat and bone cells is suggested 
by the presence of receptors for fatty acids ${ }^{28}$ and adipokines, such as leptin and adiponectin, ${ }^{29}$ on both osteoblasts and osteoclasts. Two types of interactions have been suggested: systemic and local. ${ }^{30}$ Experimental studies indicate that bone marrow fat cells can inhibit the function and survival of osteoblasts while stimulating osteoclast differentiation and function. This local or paracrine interaction depends on locally produced fatty acids and adipokines. The notion of systemic interactions is partly based on the potential activation of the same bone cell receptors by circulating fatty acids and adipokines produced by extra-osseous adipose tissue. It is also partly based on a variety of other observations, such as the effect of hyperlipidemia in promoting osteoclastic potential of mouse bone marrow cells examined ex vivo, ${ }^{31}$ and on the effect of an atherogenic high fat diet in mice $^{32}$ in reducing vertebral bone mineralisation, a process that appears to involve reduced marrow expression of osteocalcin derived from osteoclasts. A relationship has also been reported between visceral adipose tissue mass and fat in the lumbar vertebrae of humans ${ }^{19}$ although in the study of Shen et al. the relationship between volume of bone marrow fat and BMD persisted after adjustment for visceral adipose tissue volume which was measured by MRI.

Yet another theoretical possibility that may help explain the inverse bone adipose tissue (or fat)-mineral relationship concerns the effects of other systemic factors, such as circulating hormones that simultaneously influence bone cells and intra-osseous fat cells. For example, a recent study ${ }^{19}$ found an inverse relationship between fat in the lumbar vertebrae of humans, measured by magnetic resonance spectroscopy (MRS) (see below) and circulating insulin-like growth factor 1 concentration, which persisted after adjusting for age and body mass index. Studies in mice found that low insulin-like growth factor 1 is associated with reduced bone size and trabercular bone density, reduced expression of transcription factors involved in osteoblast differentiation, and an increase in bone marrow fat. ${ }^{33}$ Furthermore, since there is insulin signalling in bone cells, it would be interesting to explore the intriguing possibility of insulin resistance in bone metabolism and whether this parallels insulin resistance in intra- and extra-osseous adipose tissue. Irrespective of the mechanisms involved there is growing evidence that bone marrow adipose tissue is linked to systemic influences and systemic energy metabolism. ${ }^{29}$ The molecular biology of the signalling processes, which is rapidly evolving, suggests that many factors are involved in complex interactive processes. Since human osteoclasts are continuously turning over there is the possibility of modulating their turnover ${ }^{34}$ (osteoblast lifespan 10-15 days compared with $\sim 90$ days for osteoblasts) ${ }^{34}$ and there is also the possibility of cross-talk between these cells, which are derived from the haemopoietic rather than the mesangial cell lines, and the haemopoietic cells in red marrow that produce blood cells. While there is little information on these issues, there is clear evidence that interactions occur between yellow and red marrow. Substantial blood loss or the development haemolytic anaemia in adult life can lead to rapid replacement of yellow marrow with red marrow, reducing the total fat content of marrow and altering bone adipose tissue (or fat)-mineral relationships.

Understanding the mechanisms of cross-talk or communication between different types of cells in bone may not only help explain the inverse bone adipose tissue (or fat)-mineral relationships but also identify strategies for preventing and treating osteoporosis. A recent randomised placebo-control study in humans involving the drug rosiglitazone, ${ }^{35}$ which activates peroxisome proliferatoractivated receptor- $\gamma$, has surprisingly reported a tendency for both BMD (measured by DXA) and bone fat (by MRS) to decrease. Changes in opposite directions might have been expected (since laboratory studies have shown that activation of peroxisome proliferator-activated receptor- $\gamma$ directs differentiation of mesenchymal cells towards the adipocyte cell line (more fat) at the expense of osteoblast formation (less bone mass)). ${ }^{36,37}$ Much more needs to be understood about the underlying mechanisms controlling bone mass and function before novel pharmacological strategies to treat or prevent osteoporosis can be successfully implemented in clinical practice.

\section{METHODOLOGICAL ISSUES}

Methodological issues associated with establishing bone adipose tissue (or fat)-mineral relationships also need consideration since they have more general implications for biomedical research. First, in assessing BMD using DXA at least two potential errors can arise from the presence of fat. One relates to the inhomogeneous distribution of fat around the projected bone (it is assumed that the fat in front and behind bone is similar to that in the other areas surrounding the bone). The other relates to the presence of intra-osseous fat. With an assumed variability (s.d.) of $\pm 10 \%$ for the proportion of fat in lumbar vertebrae it was estimated, ${ }^{38}$ using data from three studies, that this would translate to an error in BMD estimation of $\pm 0.4 \%$ (s.d.) to $\pm 3 \% .^{38-40}$ Since the variability in BMD in the study of Shen et al. is much greater than this (about $15 \%$ when s.d. is expressed as a percentage of the mean BMD) the error arising from the presence of intra-osseous fat is likely to be small.

Second, since DXA scanning is a two-dimensional process the amount of bone mineral is expressed in relation to a projected bone area (areal density (areal BMD); $\mathrm{g} / \mathrm{cm}^{2}$ ), from which the total mineral content $(\mathrm{BMC})$ of the bone or region of interest can be calculated $(B M C=$ areal $B M D \times$ bone projected area). Some studies have chosen to use only areal $B M D^{8,11,13}$ to report their results, as in the study of Shen et al., ${ }^{1}$ while others use both areal $\mathrm{BMD}$ and $\mathrm{BMC}^{3,9,12}$ In many adult studies there is concordance between BMD and BMC, but this is not always the case. The following examples are used to illustrate how discordance between areal BMD and BMC can influence the study findings and/or conclusions. One study reported that $99 \%$ of peak BMD of the spine occurred at 23 years whereas peak BMC probably occurred after 32 years ${ }^{9}$ another study ${ }^{41}$ reported peak BMD at the femoral neck of Hispanics at 20 years and BMC at 29 years, and yet another study ${ }^{2}$ involving young American women, $99 \%$ of the peak whole body BMD was established by age 22 and BMC by age 26 years. In a longitudinal Canadian study, ${ }^{10}$ changes in BMC and BMD occurred in parallel but there was some discordance in the ranking order of different geographic regions, according to whether peak BMD and BMC was used as the reference indicator. A noteworthy example of discordance concerns a systematic review with meta-analysis which found that birth weight had a highly significant effect on total BMC in the adult (larger newly born babies end up with more total bone mineral) but not on BMD. ${ }^{42}$ This difference can at least be partly explained by the greater adult height (implying longer and thicker bones) in individuals with higher birth weight, which has been demonstrated consistently in cohort studies of this type. An increase in height is usually associated with a much greater increase in $B M C$ than in areal $B M D,{ }^{43-45}$ which is not surprising since total BMC depends not only on the extra mineral associated with slightly thicker bones (reflected by an increase in areal BMD and increased bone width) but also by the increase in bone length. Particularly, short individuals are expected to have reduced areal BMD (less depth for X-rays to penetrate) and reduced $T$ scores, but not necessarily reduced volumetric bone density, which appears to show little variation with height.

Third, the method of measuring fat or adipose tissue (not all of which is fat) and the method of quantifying it can also influence the strength of bone adipose tissue (or fat)-mineral relationships and potentially the conclusions that emerge. The volume of adipose tissue in a selected space or region of interest can 
be measured by MRI or computed tomography and expressed as the entire amount $(\mathrm{ml})$ present in that space, the amount present per unit volume, and even the amount per unit projected area when this is established by DXA. Relationships with other variables such as BMD or BMC may also vary. In the study of Shen et al., the total volume of pelvic adipose tissue was measured semiquantitatively by MRI and related to areal BMD. In contrast to MRI which measures adipose tissue volume in regions of interest, MRS obtains signals from fat and water in cuboidal areas of tissues (rather than from the whole tissue or region of interest), and fat is expressed as a proportion of the fat plus water volume (rather than as a proportion of the total volume of the tissue or region of interest), leaving some uncertainty as to whether fat + water account for a large or small proportion of the total bone volume. Given that a variety of methods and indices have been used to describe the amount of fat and mineral in bone, it is not surprising that many different combinations of these have been used to examine bone adipose tissue (or fat) mineral relationships, among them being the following: fat ( $\mathrm{ml}$ or $\mathrm{L})-\mathrm{BMD}^{23}$ as in the study of Shen et al. ${ }^{1}$; fat/fat + water-areal $\mathrm{BMD}^{20,21}$ fat/water-areal $\mathrm{BMD},{ }^{19,46} \mathrm{fat} / \mathrm{fat}+$ water-cortical bone $(\mathrm{ml})$ and adipose tissue volume fraction/total volume fraction. ${ }^{16}$ Care should be taken not to use these indices and relationships interchangeably since they have different physiological and statistical significance. Those involving relationships between MRI (or MRS) to measure adipose tissue (or fat), and DXA to measure bone mineral, relate an absolute volume of adipose tissue (or fat volume fraction) to areal $\mathrm{BMD}^{19-21,46}$ which is neither an absolute volume (or mass) nor volume fraction (or mass fraction). It is interesting that many studies examining bone-fat relationships using MRI (or MRS) to assess adipose tissue (or fat) on the one hand, and DXA to assess bone mineral on the other, have not controlled for height ${ }^{1,17,19-24,46}$ (see Discussion above concerning the influence of height on BMD and BMC).

Finally, the perceived strength of relationships between two components of a tissue can be influenced by subtle statistical relationships that may result in auto-correlation in some circumstances with important implications about how the relationships should be interpreted from a biological perspective. In a fixed space containing only two components (for example, bone marrow versus non-marrow; cortical and non-cortical bone tissue, fat and water) a change in the fraction of one component, no matter what underlying mechanisms are involved, will automatically reflect the change in the proportion of the other component in the opposite direction, producing a perfect inverse relationship between the two components. The same applies to relationships involving absolute amounts of two components when the volume of the space is fixed, an issue of some relevance to adult bone, which has fairly fixed rigid dimensions. In models with more than two components there is still potential for negative auto-correlation, especially if the additional components are minor and make only a small overall fractional contribution to the variable composition of that space. The situation becomes more complicated when the volume of that space also changes, because this introduces more 'noise' into the relationships. By analogy to real life an increase in the bone space can be considered to represent larger bones from taller, heavier people, who are expected to have more mineral and fat, than smaller bones from shorter, lighter people. Since bone adipose tissue (or fat)-mineral relationships have been established using a variety of different indices, while adjusting for a variable number of confounding variables, often without height (see above) there is still the possibility of some residual non-independent autocorrelation and/or variable noise from confounding variables that can affect the strength of the bone adipose tissue (or fat)-mineral relationships. Mathematical modelling could help assess the extent to which such effects influence bone adipose tissue (or fat)-mineral relationships, our concepts about the underlying mechanisms and the biological processes that determine bone structure and function.

\section{CONFLICT OF INTEREST}

The author declares no conflict of interest.

\author{
M Elia ${ }^{1,2}$ \\ ${ }^{1}$ Institute of Human Nutrition, University of Southampton, \\ Southampton, UK and \\ ${ }^{2}$ Academic Unit: Human Development and Health, Faculty of \\ Medicine, University of Southampton, Southampton, UK
} E-mail: elia@soton.ac.uk

\section{REFERENCES}

1 Shen W, Chen J, Gantz M, Punyanitya M, Heymsfield SB, Gallagher D et al. MRI-measured pelvic bone marrow adipose tissue is inversely related to DXA-measured bone mineral in younger and older adults. Eur J Clin Nutr 2012; e-pub ahead of print 11 April 2012; doi:10.1038/ejcn.2012.35.

2 Teegarden D, Proulx WR, Martin BR, Zhao J, McCabe GP, Lyle RM et al. Peak bone mass in young women. J Bone Miner Res 1995; 10: 711-715.

3 Nguyen TV, Maynard LM, Towne B, Roche AF, Wisemandle W, Li J et al. Sex differences in bone mass acquisition during growth: the Fels Longitudinal Study. J Clin Densitom 2001; 4: 147-157.

4 Recker RR, Davies KM, Hinders SM, Heaney RP, Stegman MR, Kimmel DB. Bone gain in young adult women. JAMA 1992; 268: 2403-2408.

5 Szulc P, Marchand F, Duboeuf F, Delmas PD. Cross-sectional assessment of age-related bone loss in men: the MINOS study. Bone 2000; 26: 123-129.

6 Lorentzon M, Mellstrom D, Ohlsson C. Age of attainment of peak bone mass is site specific in Swedish men--The GOOD study. J Bone Miner Res 2005; 20: 1223-1227.

7 Baxter-Jones AD, Faulkner RA, Forwood MR, Mirwald RL, Bailey DA. Bone mineral accrual from 8 to 30 years of age: an estimation of peak bone mass. $J$ Bone Miner Res 2011; 26: 1729-1739.

8 Tan LJ, Lei SF, Chen XD, Liu MY, Guo YF, Xu H et al. Establishment of peak bone mineral density in Southern Chinese males and its comparisons with other males from different regions of China. J Bone Miner Metab 2007; 25: 114-121.

9 Lin YC, Lyle RM, Weaver CM, McCabe LD, McCabe GP, Johnston CC et al. Peak spine and femoral neck bone mass in young women. Bone 2003; 32: 546-553.

10 Berger C, Goltzman D, Langsetmo L, Joseph L, Jackson S, Kreiger N et al. Peak bone mass from longitudinal data: implications for the prevalence, pathophysiology, and diagnosis of osteoporosis. J Bone Miner Res 2010; 25: 1948-1957.

11 Shivane VK, Sarathi V, Lila AR, Bandgar T, Joshi SR, Menon PS et al. Peak bone mineral density and its determinants in an Asian Indian population. J Clin Densitom 2012; 15: 152-158.

12 Kadam N, Khadilkar A, Chiplonkar S, Khadilkar V, Mughal Z. Variation in lumbar spine bone mineral content by age and gender in apparently healthy Indians. $J$ Bone Miner Metab 2009; 27: 705-712.

13 Nguyen HT, von Schoultz B, Pham DM, Nguyen DB, Le QH, Nguyen DV et al. Peak bone mineral density in Vietnamese women. Arch Osteoporos 2009; 4(1-2): 9-15.

14 Walsh JS, Henry YM, Fatayerji D, Eastell R. Lumbar spine peak bone mass and bone turnover in men and women: a longitudinal study. Osteoporos Int 2009; 20: 355-362.

15 Snyder WS, Cook MJ, Nasset ES, Karhausen LR, Howells GP, Tipton IH. Report of the task group on reference man. International Commission on Radiological Protection No 23. Pergamon Press: Oxford, 1975.

16 Justesen J, Stenderup K, Ebbesen EN, Mosekilde L, Steiniche T, Kassem M. Adipocyte tissue volume in bone marrow is increased with aging and in patients with osteoporosis. Biogerontology 2001; 2: 165-171.

17 Griffith JF, Yeung DK, Ma HT, Leung JC, Kwok TC, Leung PC. Bone marrow fat content in the elderly: a reversal of sex difference seen in younger subjects. J Magn Reson Imaging 2012; 36: 225-230.

18 Goodsitt MM, Hoover P, Veldee MS, Hsueh SL. The composition of bone marrow for a dual-energy quantitative computed tomography technique. A cadaver and computer simulation study. Invest Radiol 1994; 29: 695-704.

19 Bredella MA, Torriani M, Ghomi RH, Thomas BJ, Brick DJ, Gerweck AV et al. Vertebral bone marrow fat is positively associated with visceral fat and inversely associated with IGF-1 in obese women. Obesity (Silver Spring) 2011; 19: 49-53.

20 Liney GP, Bernard CP, Manton DJ, Turnbull LW, CM Langton. Age, gender, and skeletal variation in bone marrow composition: a preliminary study at 3.0 Tesla. J Magn Reson Imaging 2007; 26: 787-793.

21 Slade JM, Coe LM, Meyer RA, McCabe LR. Human bone marrow adiposity is linked with serum lipid levels not T1-diabetes. J Diabetes Complications 2012; 26: 1-9. 
22 Schellinger D, Lin CS, Lim J, Hatipoglu HG, Pezzullo JC, Singer AJ. Bone marrow fat and bone mineral density on proton MR spectroscopy and dual-energy X-ray absorptiometry: their ratio as a new indicator of bone weakening. $A J R A m J$ Roentgenol 2004; 183: 1761-1765.

23 Shen W, Chen J, Punyanitya M, Shapses S, Heshka S, Heymsfield SB. MRI-measured bone marrow adipose tissue is inversely related to DXA-measured bone minera in Caucasian women. Osteoporos Int 2007; 18: 641-647.

24 Wehrli FW, Hopkins JA, Hwang SN, Song HK, Snyder PJ, Haddad JG. Crosssectional study of osteopenia with quantitative MR imaging and bone densitometry. Radiology 2000; 217: 527-538.

25 Bianco P, Gehron Robey P. Marrow stromal stem cells. J Clin Invest 2000; 105 1663-1668.

26 Gimble JM, Robinson CE, Wu X, Kelly KA. The function of adipocytes in the bone marrow stroma: an update. Bone 1996; 19: 421-428.

27 Ducy $P$. The role of osteocalcin in the endocrine cross-talk between bone remodelling and energy metabolism. Diabetologia 2011; 54: 1291-1297.

28 Cornish J, MacGibbon A, Lin JM, Watson M, Callon KE, Tong PC et al. Modulation of osteoclastogenesis by fatty acids. Endocrinology 2008; 149: 5688-5695.

29 Lecka-Czernik B. Marrow fat metabolism is linked to the systemic energy metabolism. Bone 2012; 50: 534-539.

30 Duque G. Bone and fat connection in aging bone. Curr Opin Rheumatol 2008; 20 429-434.

31 Oh SR, Sul OJ, Kim YY, Kim HJ, Yu R, Suh JH et al. Saturated fatty acids enhance osteoclast survival. J Lipid Res 2010; 51: 892-899.

32 Parhami F, Tintut Y, Beamer WG, Gharavi N, Goodman W, Demer LL. Atherogenic high-fat diet reduces bone mineralization in mice. J Bone Miner Res 2001; 16: 182-188.

33 Rosen CJ, Ackert-Bicknell CL, Adamo ML, Shultz KL, Rubin J, Donahue LR et al. Congenic mice with low serum IGF-I have increased body fat, reduced bone mineral density, and an altered osteoblast differentiation program. Bone 2004; 35: 1046-1058.

34 Parfitt AM. Osteoclast precursors as leukocytes: importance of the area code. Bone 1998; 23: 491-494.

35 Harslof T, Wamberg L, Moller L, Stodkilde-Jorgensen H, Ringgaard S, Pedersen SB et al. Rosiglitazone decreases bone mass and bone marrow fat. J Clin Endocrinol Metab 2011; 96: 1541-1548.
36 Muruganandan S, Roman AA, Sinal CJ. Adipocyte differentiation of bone marrowderived mesenchymal stem cells: cross talk with the osteoblastogenic program. Cell Mol Life Sci 2009; 66: 236-253.

37 Lazarenko OP, Rzonca SO, Hogue WR, Swain FL, Suva LJ, Lecka-Czernik B. Rosiglitazone induces decreases in bone mass and strength that are reminiscent of aged bone. Endocrinology 2007; 148: 2669-2680.

38 Blake GM, Griffith JF, Yeung DK, Leung PC, Fogelman I. Effect of increasing vertebral marrow fat content on BMD measurement, T-Score status and fracture risk prediction by DXA. Bone 2009; 44: 495-501.

39 Sorenson JA. Effects of nonmineral tissues on measurement of bone mineral content by dual-photon absorptiometry. Med Phys 1990; 17 905-912.

40 Bolotin HH. DXA in vivo BMD methodology: an erroneous and misleading research and clinical gauge of bone mineral status, bone fragility, and bone remodelling. Bone 2007; 41: 138-154.

41 Berenson $A B$, Rahman M, Wilkinson G. Racial difference in the correlates of bone mineral content/density and age at peak among reproductive-aged women. Osteoporos Int 2009; 20: 1439-1449.

42 Baird J, Kurshid MA, Kim M, Harvey N, Dennison E, Cooper C. Does birthweight predict bone mass in adulthood? A systematic review and meta-analysis. Osteoporos Int 2011; 22: 1323-1334.

43 Deng HW, Xu FH, Davies KM, Heaney R, Recker RR. Differences in bone minera density, bone mineral content, and bone areal size in fracturing and non-fracturing women, and their interrelationships at the spine and hip. $J$ Bone Miner Metab 2002; 20: 358-366.

44 Heymsfield SB, Heo M, Thomas D, Pietrobelli A. Scaling of body composition to height: relevance to height-normalized indexes. Am J Clin Nutr 2011; 93 736-740.

45 Valero C, Zarrabeitia MT, Hernandez JL, Zarrabeitia A, Gonzalez-Macias J, Riancho JA. Bone mass in young adults: relationship with gender, weight and genetic factors. J Intern Med 2005; 258: 554-562.

46 Shih TT, Chang CJ, Hsu CY, Wei SY, Su KC, Chung HW. Correlation of bone marrow lipid water content with bone mineral density on the lumbar spine. Spine 2004; 29: $2844-2850$ 